\title{
Effect of Gestational Diabetes on Interventricular Septum Thickness in Newborns in the Golestan Province, Iran
}

\author{
Hassan Esmaeili ${ }^{1}$, Bagher Pahlavanzade ${ }^{2}$, Mohsen Ebrahimi*3 \\ 1. Gorgan Congenital Malformations Research Center, Golestan University of Medical Sciences, Gorgan, \\ Iran; orcid id: 0000-0001-8205-0869 \\ 2 Department of Biostatistics, School of Paramedical Sciences, Shahid Beheshti University of Medical \\ Sciences, Tehran, Iran; orcid id: 0000-0002-4876-1058 \\ 3. Neonatal and Children's Health Research Center, Golestan University of Medical Sciences, Gorgan, Iran; \\ orcid id: 0000-0003-4127-9258
}

\begin{abstract}
Background and objectives: Despite advances in prenatal care, there is a high rate of morbidity and mortality in infants of diabetic mothers. Interventricular septal hypertrophy is a well-known congenital heart abnormality in neonates of mothers with gestational diabetes. In this study, we investigate the effect of gestational diabetes mellitus on interventricular septum thickness.
\end{abstract}

Methods: In this cross-sectional cohort study, 42 neonates from mothers with gestational diabetes mellitus and 42 neonates from non-diabetic mothers were selected from gynecology ward of Sayyad Shirazi Hospital in Gorgan (Iran) between April 2016 and April 2017. Ventricular septum thickness in neonates was measured by M-mode echocardiography. Comparison of septum thickness and frequency of septal hypertrophy between the two groups was performed using t-test, Mann-Whitney test and chi-square test. All statistical analyses were preformed in SPSS 16 at significance level of 0.05 .

Results: The mean septum thickness was $4.51 \pm 1.58 \mathrm{~mm}$ in newborns of non-diabetic mothers and $5.84 \pm 1.44 \mathrm{~mm}$ in newborns of diabetic mothers $(\mathrm{P}<0.001)$. Septal hypertrophy (thickness of $\geq 6$ $\mathrm{mm})$ was significantly more common in newborns of diabetic mothers $(\mathrm{P}=0.029)$. In addition, we found no significant difference in septum thickness between newborns of diabetic mothers receiving diet or insulin therapy.

Conclusion: Overall, our findings suggest that there is a significant correlation between gestational diabetes and ventricular septal hypertrophy. In addition, glycemic control with diet or insulin therapy has no significant impact on septum thickness.

Keywords: Gestational diabetes mellitus, ventricular septum, Neonates

$\begin{array}{lll}\text { Received: } 20 \text { Oct } 2019 & \text { Revised: } 17 \text { Feb } 2020 \quad \text { Published: } 24 \text { Feb } 2020\end{array}$

*Correspondence: Mohsen Ebrahimi, Tel: +98(17)32226013, Email: dr.ebrahimi2019@gmail.com 


\section{INTRODUCTION}

Development of diabetes during pregnancy increases the risk of morbidity and fetal death (1). Gestational diabetes accounts for $80 \%$ of all cases of diabetes during pregnancy, followed by pre-pregnancy diabetes and glucose intolerance (2). Changes in glucose metabolism during pregnancy have short- and long-term effects on the fetus $(3,4)$.

Hypertrophic cardiomyopathy affects $10 \%$ to $40 \%$ of infants born to diabetic mothers. The functional impact of septal hypertrophy in infants can vary from an asymptomatic form to congestive heart failure due to left ventricular outflow tract obstruction. Cardiac hypertrophy in infants of non-diabetic mothers is rare $(5,6)$, while gestational diabetes causes an 18-fold increase in the relative risk of developing septal hypertrophy (7).

The exact causes of gestational diabetesinduced septal hypertrophy in fetus are not clear. Although hyperglycemia is the hallmark of diabetes, results of studies on the possible correlation of maternal glycemia with fetal septal hypertrophy have been inconsistent $(6,8-13)$.

Neonates born to mothers with glycemic control are also at risk of developing septal hypertrophy (14-16). Surprisingly, infants of diabetic mothers under strict glycemic control, despite having very low glycosylated fetal hemoglobin $(\mathrm{HbF} 1 \mathrm{c})$ levels, are also at high risk for septal hypertrophy (17).

Although the effect of gestational diabetes on interventricular septum thickness have been investigated in different populations $(1,4,18$ 21), a limited number of studies have been performed on this issue in Iran $(22,23)$. Therefore, we aimed to study interventricular septum thickness in neonates of diabetic and non-diabetic mothers in an Iranian population.

\section{MATERIALS AND METHODS}

In this cross-sectional cohort study, study population consisted of all pregnant women referred to the gynecology ward of Sayyad Shirazi Hospital of Gorgan (Iran) between April 2016 and April 2017. Subjects were selected via convenience sampling. Mothers were divided into a diabetic and non-diabetic group based on medical history and interviews. The interventricular septum thickness was measured in newborns from both groups (each group contained 42 newborns). Written consent was obtained from the subjects' parents after explaining the research objectives. Inclusion criteria for mothers were no history of hyperlipidemia, preeclampsia/eclampsia, hypertension, hypothyroidism, hyperthyroidism, smoking, drug abuse, alcoholism and heart, liver and renal failure. Neonates with hypoglycemia or electrolyte imbalance, hyperbilirubinemia, preterm birth, as well as those requiring hospitalization for any reason such as phototherapy were excluded.

Interventricular septum thickness was determined by fetal two-dimensional Doppler echocardiography using M-Mode (1). A 12lead electrocardiogram (ECG) was also performed for all newborns for 10 seconds at the heart clinic of the hospital by the same operator.

Comparison of diabetic and non-diabetic mothers in terms of demographic variables and characteristics of newborns were also performed. Neonates of diabetic mothers were divided into two groups based on their glycemic control during pregnancy and insulin therapy. Normal distribution of data for septal hypertrophy was assessed using the Kolmogorov-Smirnov test. Given the nonnormal distribution of data, comparisons were made between the two groups using the Mann-Whitney test. Neonates were divided into two groups based on interventricular septum thickness of greater than $6 \mathrm{~mm}$ and less than $6 \mathrm{~mm}$, and differences between the groups were assessed using chi-square test. All statistical analyses were performed using SPSS 16 at significance level of 0.05 .

\section{RESULTS}

Table 1 shows demographic characteristics of diabetic and non-diabetic mothers. There was no significant difference between gender of newborns from diabetic and non-diabetic mothers. The mean age of newborns at the time of study did not differ significantly $(\mathrm{P}=0.43)$. In addition, the mean birth weight of newborns did not differ significantly $(\mathrm{P}=0.57)$. 
Table 1. Comparison of demographic characteristics of neonates of diabetic mothers and nondiabetic mothers in the Golestan Province, Iran

\begin{tabular}{|c|c|c|c|c|}
\hline \multicolumn{2}{|c|}{ Variable } & Non-diabetic & Diabetic & \multirow{2}{*}{ P-value } \\
\hline \multirow{2}{*}{ Gender of newborn } & Male & $19(45 \%)$ & $20(47.7 \%)$ & \multirow{2}{*}{1} \\
\cline { 2 - 4 } & Female & $23(54.7 \%)$ & $22(52.3 \%)$ & \multirow{2}{*}{0.53} \\
\hline \multirow{2}{*}{ Type of delivery } & Caesarean section & $28(66.6 \%)$ & $33(78.5 \%)$ & $11(26 \%)$ \\
\cline { 2 - 4 } & Vaginal delivery & $14(33.3 \%)$ & $3.04 \pm 1.14$ & 0.57 \\
\hline \multicolumn{2}{|r|}{ Birth weight (kg) } & $3.07 \pm 1.2$ & $5.12 \pm 1.68$ & 0.43 \\
\hline \multicolumn{2}{|r|}{ Age of newborn (days) } & $5.5 \pm 1.38$ & $38.1 \pm 1.57$ & 0.37 \\
\hline
\end{tabular}

Table 2. Mean ventricular septum thickness in neonates of mothers with gestational diabetes mellitus and in those from non-diabetic mothers in the Golestan Province, Iran

\begin{tabular}{|c|c|c|c|}
\hline Variable & $\begin{array}{c}\text { Newborns of } \\
\text { diabetic mothers }\end{array}$ & $\begin{array}{c}\text { Newborns of non- } \\
\text { diabetic mothers }\end{array}$ & P-value \\
\hline Mean septum thickness (mm) & $5.84 \pm 1.44$ & $4.51 \pm 1.58$ & 0.001 \\
\hline Frequency of septal hypertrophy & $17(38 \%)$ & $6(14.2 \%)$ & 0.029 \\
\hline
\end{tabular}

Table 3. Comparison of mean interventricular septum thickness between newborns of mothers under diet therapy and insulin therapy

\begin{tabular}{|c|c|c|c|}
\hline Variable & Under insulin therapy & Under diet therapy & P-value \\
\hline $\begin{array}{c}\text { Mean interventricular } \\
\text { septum thickness }(\mathbf{m m})\end{array}$ & $6.14 \pm 1.35$ & $5.69 \pm 1.5$ & 0.34 \\
\hline
\end{tabular}

As shown in table 2, the mean septum thickness was $4.51 \pm 1.58 \mathrm{~mm}$ in newborns of non-diabetic mothers and $5.84 \pm 1.44 \mathrm{~mm}$ in newborns of diabetic mothers $(\mathrm{P}<0.001)$. Septal hypertrophy was significantly more common in newborns of diabetic mothers $(\mathrm{P}=0.029)$.

The effect of insulin and diet therapy on incidence of septal hypertrophy was investigated in newborns of diabetic mothers. For this purpose, mothers were divided into two groups of insulin therapy $(n=14)$ and diet therapy $(n=28)$. As shown in table 3, mean septum thickness did not differ significantly between the two groups $(\mathrm{P}=0.34)$.

\section{DISUCSSION}

The present study is one of the few to investigate the relationship between the incidence of interventricular septal hypertrophy in neonates and maternal gestational diabetes in Iran. Our findings showed that ventricular septum was thicker in neonates of diabetic mothers than in neonates of non-diabetic mothers. On the other hand, glycemic control in diabetic mothers during pregnancy had no effect on ventricular septum.

Many studies have reported a significant relationship between gestational diabetes mellitus and septal hypertrophy $(1,4,18,19$, 22). For example, in a study by Russell et al., ventricular septum was significantly thicker in fetus of mothers with gestational diabetes in the last trimester of pregnancy (18). Ghandi et al. also reported that septal hypertrophy was more common in neonates of diabetic mothers (22).

Although some studies reported no association between maternal glucose level and septal hypertrophy in neonates $(10,11)$, septal hypertrophy occurs in $35 \%$ of neonates from diabetic mothers. 
In the present study, we found no significant difference in septum thickness between newborns of diabetic mothers receiving diet or insulin therapy. A high incidence of septal hypertrophy has been reported in diabetic mothers with strict glycemic control. Some studies also reported that septal hypertrophy is significantly more common in diabetic mothers with strict glycemic control and glycosylated hemoglobin levels significantly lower than fetal glucose levels $(14,16,22)$.

Other factors resulting from gestational diabetes, such as nutrient transfer via altered placenta or hormonal imbalance may be related to septal hypertrophy (24). A study by Gordon et al. found that rapid and temporary exposure to hyperglycemia results in ventricular septal hypertrophy in newborns, even in those from non-diabetic mothers (24).

In the present study, we did not measure glucose levels during the pregnancy period, which can be considered a limitation of our study. In addition, the small population size limited elimination of the effect of possible confounding factors.

\section{CONCLUSION}

Overall, our findings suggest that there is a significant correlation between gestational diabetes and ventricular septal hypertrophy. In addition, glycemic control with diet or insulin therapy has no significant impact on septum thickness.

\section{DECLARATIONS}

\section{Funding}

This study was supported by a grant from the Ischemic Disorders Research Center of the Golestan University of Medical Sciences, Iran.

\section{Ethics approvals and consent to participate}

The study was approved by the ethics committee of the Golestan University of Medical Sciences, Iran. A written informed consent was taken from all subjects prior to participation.

\section{Conflict of interest}

The authors declare that there is no conflict of interest.

\section{REFERENCES}

1. Arslan D, Guvenc O, Cimen D, Ulu H, Oran B. Prolonged QT dispersion in the infants of diabetic mothers. Pediatric cardiology. 2014;35(6):1052-6. [DOI:10.1007/s00246-014-0897-3]

2. Chen C, Gui YH, Ren YY, Shi LY. The impacts of maternal gestational diabetes mellitus (GDM) on fetal hearts. Biomedical and Environmental Sciences. 2012;25(1):15-22.

3. Veglio M, Chinaglia A, Cavallo-Perin P. QT interval, cardiovascular risk factors and risk of death in diabetes. Journal of endocrinological investigation. 2004;27(2):175-81. [DOI:10.1007/BF03346265]

4. Arslan D, Oran B, Vatansev H, Cimen D, Guvenc O. The usefulness of plasma asymmetric dimethylarginine (ADMA) levels and tissue doppler echocardiography for heart function in term infants born to mothers with gestational diabetes mellitus. The Journal of MaternalFetal \& Neonatal Medicine. 2013;26(17):1742-8. [DOI:10.3109/14767058.2013.798288]

5. Mongiovì M, Fesslova V, Fazio G, Barbaro G, Pipitone S. Diagnosis and prognosis of fetal cardiomyopathies: a review. Current pharmaceutical design. 2010;16(26):2929-34. [DOI:10.2174/138161210793176428]

6. Vela-Huerta MM, Vargas-Origel A, Olvera-López A. Asymmetrical septal hypertrophy in newborn infants of diabetic mothers. American journal of perinatology. 2000;17(02):089-94. [DOI:10.1055/s2000-9267]

7. Abu-Sulaiman RM, Subaih B. Congenital heart disease in infants of diabetic mothers: echocardiographic study. Pediatric cardiology. 2004;25(2):137-40. [DOI:10.1007/s00246-003-0538-8]

8. Cooper MJ, Enderlein MA, Tarnoff H, Rogé CL. Asymmetric septal hypertrophy in infants of diabetic mothers: fetal echocardiography and the impact of maternal diabetic control. American journal of diseases of children. $1992 ; 146(2): 226-9$. [DOI:10.1001/archpedi.1992.02160140092027]

9. El-Ganzoury MM, El-Masry SA, El-Farrash RA, Anwar M, Abd Ellatife RZ. Infants of diabetic mothers: echocardiographic measurements and cord blood IGF-I and IGFBP-1. Pediatric diabetes. 2012;13(2):189-96.

5448.2011.00811.x]

[DOI:10.1111/j.1399-

10. Åman J, Hansson U, Östlund I, Wall K, Persson B. Increased fat mass and cardiac septal hypertrophy in newborn infants of mothers with well-controlled diabetes during pregnancy. Neonatology. 2011;100(2):147-54. [DOI:10.1159/000323741]

11. Sheehan PQ, Rowland TW, Shah BL, McGravey VJ, Reiter EO. Maternal diabetic control and hypertrophic cardiomyopathy in infants of diabetic mothers. Clinical Pediatrics. 1986;25(5):266-71. [DOI:10.1177/000992288602500507]

12. Ren Y, Zhou Q, Yan Y, Chu C, Gui Y, Li X. Characterization of fetal cardiac structure and function detected by echocardiography in women with normal 
pregnancy and gestational diabetes mellitus. Prenatal diagnosis. 2011;31(5):459-65. [DOI:10.1002/pd.2717]

13. Alsweiler JM, Harding JE, Bloomfield FH. Tight glycemic control with insulin in hyperglycemic preterm babies: a randomized controlled trial. Pediatrics. 2012;129(4):639-47.

[DOI:10.1542/peds.2011-2470]

14. Weber H, Botti J, Baylen B. Sequential longitudinal evaluation of cardiac growth and ventricular diastolic filling in fetuses of well controlled diabetic mothers. Pediatric cardiology. 1994;15(4):1849. [DOI:10.1007/BF00800673]

15. Gandhi JA, Zhang XY, Maidman JE. Fetal cardiac hypertrophy and cardiac function in diabetic pregnancies. American journal of obstetrics and gynecology. 1995;173(4):1132-6. [DOI:10.1016/00029378(95)91339-4]

16. Weber HS, Copel JA, Reece EA, Green J, Kleinman CS. Cardiac growth in fetuses of diabetic mothers with good metabolic control. The Journal of pediatrics. 1991;118(1):103-7. [DOI:10.1016/S00223476(05)81858-X]

17. Oberhoffer R, Högel J, Stoz F, Kohne E, Lang D. Cardiac and extracardiac complications in infants of diabetic mothers and their relation to parameters of carbohydrate metabolism. European journal of pediatrics. 1997;156(4):262-5. [DOI:10.1007/s004310050596]

18. Russell NE, Foley M, Kinsley BT, Firth RG, Coffey M, McAuliffe FM. Effect of pregestational diabetes mellitus on fetal cardiac function and structure. American journal of obstetrics and gynecology. 2008;199(3):312. e1-e7. [DOI:10.1016/j.ajog.2008.07.016]
19. Lin X, Yang P, Reece EA, Yang P. Pregestational type 2 diabetes mellitus induces cardiac hypertrophy in the murine embryo through cardiac remodeling and fibrosis. American journal of obstetrics and gynecology. 2017;217(2):216. e1-e13. [DOI:10.1016/j.ajog.2017.04.008]

20. Vela-Huerta MM, Amador-Licona N, Villagomez HVO, Ruiz AH, Guizar-Mendoza JM. Asymmetric Septal Hypertrophy in Appropriate for Gestational Age Infants Born to Diabetic Mothers. Indian pediatrics. 2019;56(4):314-6. [DOI:10.1007/s13312-019-1522-6]

21. Babović I, Arandjelović $\mathrm{M}$, Plešinac $\mathrm{S}$, Kontić-Vučinić O, Radunović N. Maternal glycoregulation in pregnancies complicated by diabetes mellitus in the prediction of fetal echography findings and perinatal outcomes. Journal of Obstetrics and Gynaecology Research. 2018;44(3):432-9. [DOI:10.1111/jog.13537]

22. Ghandi Y, Habibi D, Nasri K, Alinejad S, Taherahmad H, Arjmand Shabestari A, et al. Effect of well-controlled gestational diabetes on left ventricular diastolic dysfunction in neonates. The Journal of Maternal-Fetal \& Neonatal Medicine. 2019;32(13):2101-6. [DOI:10.1080/14767058.2018.1425832]

23. Semira M, Majid M, Maryam NE, Shamsollah N. Comparison of echocardiographic findings in infants of mothers with gestational diabetes and healthy mothers. Tehran Univ Med J (TUMJ).72(8):9.

24. Gordon EE, Reinking BE, Hu S, Yao J, Kua KL, Younes AK, et al. Maternal hyperglycemia directly and rapidly induces cardiac septal overgrowth in fetal rats. Journal of diabetes research. 2015;2015. [DOI:10.1155/2015/479565] 